\title{
Melatonin and health: an umbrella review of health outcomes and biological mechanisms of action
}

\author{
Pawel P. Posadzki ${ }^{1 *}$ (D, Ram Bajpai ${ }^{1}$, Bhone Myint Kyaw ${ }^{1}$, Nicola J. Roberts², Amnon Brzezinski ${ }^{3}$, \\ George I. Christopoulos ${ }^{4}$, Ushashree Divakar ${ }^{1}$, Shweta Bajpai ${ }^{1}$, Michael Soljak', Gerard Dunleavy ${ }^{1}$, Krister Jarbrink ${ }^{1}$, \\ Ei Ei Khaing Nang ${ }^{1}$, Chee Kiong Soh ${ }^{5}$ and Josip Car ${ }^{1,6}$
}

\begin{abstract}
Background: Our aims were to evaluate critically the evidence from systematic reviews as well as narrative reviews of the effects of melatonin (MLT) on health and to identify the potential mechanisms of action involved.

Methods: An umbrella review of the evidence across systematic reviews and narrative reviews of endogenous and exogenous (supplementation) MLT was undertaken. The Oxman checklist for assessing the methodological quality of the included systematic reviews was utilised. The following databases were searched: MEDLINE, EMBASE, Web of Science, CENTRAL, PsycINFO and CINAHL. In addition, reference lists were screened. We included reviews of the effects of MLT on any type of health-related outcome measure.

Results: Altogether, 195 reviews met the inclusion criteria. Most were of low methodological quality (mean -4.5, standard deviation 6.7). Of those, 164 did not pool the data and were synthesised narratively (qualitatively) whereas the remaining 31 used meta-analytic techniques and were synthesised quantitatively. Seven meta-analyses were significant with $P$ values less than 0.001 under the random-effects model. These pertained to sleep latency, pre-operative anxiety, prevention of agitation and risk of breast cancer.

Conclusions: There is an abundance of reviews evaluating the effects of exogenous and endogenous MLT on health. In general, MLT has been shown to be associated with a wide variety of health outcomes in clinically and methodologically heterogeneous populations. Many reviews stressed the need for more high-quality randomised clinical trials to reduce the existing uncertainties.
\end{abstract}

Keywords: Melatonin, Health, Effectiveness, Umbrella review, Systematic reviews, Meta-analyses

\section{Background}

Circadian rhythms are biological processes that display endogenous, entrainable oscillation cycles that last approximately 24 hours (owing to the Earth's rotation around its own axis) [1]. These rhythms tune internal physiology, behaviour and metabolism to external conditions and are considered to be a feature of most living cells and organisms [1].

\footnotetext{
* Correspondence: paul.posadzki@ntu.edu.sg

${ }^{1}$ Centre for Population Health Sciences, 11 Mandalay Road, Level 18 Clinical Sciences Building, Lee Kong Chian School of Medicine, Novena Campus, Nanyang Technological University, Singapore 308232, Singapore

Full list of author information is available at the end of the article
}

At the epicentre of circadian rhythms is melatonin (MLT) or N-acetyl-5-methoxy tryptamine, an indoleamine primarily produced by the pineal gland and secreted into the blood $[2,3]$. The indoleamine can be administered exogenously, i.e. orally, as capsules, tablets or liquids, sublingually, or as transdermal patches. It is available without prescription (over-the-counter) in many countries for the treatment of insomnia and depression. MLT synchronises the internal hormonal environment to the light-dark cycle of the external environment and controls circadian rhythms $[4,5]$. Unfortunately, at night, artificial lighting such as light-emitting diodes (LED) continues to activate the suprachiasmatic nucleus of the brain, suppressing the natural release of MLT and potentially causing health 
problems [6]. Previous studies have provided evidence of the role of MLT on the regulation of circadian rhythms as well as its connection with the development of various cancers (breast, prostate, endometrial, ovary, colorectal and skin), cardiovascular diseases, gastrointestinal and digestive problems, diabetes, obesity, depression, sleep deprivation, premature ageing and cognitive impairment [7-16].

A comprehensive, informed and up-to-date review of the current knowledge on the effects of MLT on health is not only timely but urgent, given the technological and lifestyle changes, e.g. chronodisruption, following the overwhelming use of the LEDs omnipresent in computers, smartphones and tablets.

Therefore, the objectives of this umbrella review were to evaluate the evidence for the effects of MLT on health from the published literature, specifically systematic reviews (SRs) and narrative reviews (NRs), to investigate the potential mechanisms of action and to identify which health outcomes are associated with the production and/ or supplementation of MLT.

\section{Methods}

The Cochrane Handbook for Systematic Reviews of interventions and the Preferred Reporting Items for Systematic Reviews and Meta-Analyses (PRISMA) guidelines [17] were adhered to while writing and reporting this review (Prospero registration number: CRD42016039840; available at www.crd.york.ac.uk/PROSPERO) [18].

\section{Literature search and eligibility criteria}

For the electronic search, the following databases were searched for entries from January 1996 until July 2017: MEDLINE (via Ovid), EMBASE (via Ovid), Web of Science, CENTRAL (Wiley), PsycINFO (Ovid) and CINAHL (via EBSCO). We hypothesised that any significant reviews or studies would have been captured by reviews conducted since January 1996 (our search start date). A detailed search strategy for MEDLINE is presented in the Appendix. In addition to the electronic searches, the reference lists of all eligible articles were reviewed for further potentially relevant studies. Only data from the published papers were used; the study authors were not contacted.

We included SRs (defined as research articles with a replicable methods section, e.g. searches, eligibility criteria and critical appraisal of primary studies) [19] or NRs (defined as articles without a replicable methods section) [20] of studies involving both healthy and ill individuals of any age and gender using both endogenous and exogenous MLT and MLT agonists. Reviews that relied on data from animal, human or/and in vitro studies with any type of health-related outcome measures were eligible. All SRs and NRs that are for the same associations throughout the search period regardless of the amount and level of overlap, i.e. one primary study included in two or more reviews and/or two or more identified reviews on the same topic, were eligible. We excluded reviews of plants, abstracts or review protocols and reviews not published in English.

\section{Study selection}

The data screening and selection process were performed by the first reviewer (PP) and verified and validated by a second reviewer (BMK). All identified references were imported into EndNote (X7.7.1). The search results from all the bibliographic searches were merged and duplicate records removed.

\section{Data extraction}

Working in groups of two, four authors (BMK, UD, GD and $\mathrm{SB}$ ) independently extracted relevant information from the studies included using a custom-made data extraction form. The data were subsequently validated by a fifth author (PP). The following information was extracted from the reviews included: first authors' names and publication date, total number of primary studies, total number of patients included, quality of SRs (Oxman checklist score), quality of primary studies (low, moderate or high as determined by the authors of the reviews), subject/ condition/indication, administration of MLT (dose, route, frequency and duration), details of any metaanalyses (MAs), health outcomes/effects/overall results, confounders, and any additional comments. Any disagreements were resolved by discussion between the authors.

\section{Quality assessment}

The methodological quality of SRs was independently evaluated by five reviewers using the Oxman checklist [21]. This validated tool assesses the quality of review articles across nine domains: (1) reporting of search strategy, (2) comprehensiveness of searches, (3) repeatable eligibility criteria, (4) avoidance of selection bias, (5) presence of a validity assessment tool, (6) use of the validity assessment tool, (7) robustness of data analysis, (8) appropriateness of data analysis and (9) supportiveness of conclusions. Each question was scored as 1 (fulfilled), 0 (partially fulfilled) or -1 (not fulfilled). A score of 1 or below indicates extensive flaws, 2-3 indicates the presence of major flaws, 4-5 means minor flaws and 6-9 indicates minimal or no flaws. Again, any disagreements $(N=6)$ were resolved by discussion between the authors.

\section{Statistical analysis}

The results from NRs or SRs that did not pool data quantitatively $(N=164)$ are presented narratively using descriptive tables. Sub-group analyses were conducted for the subset of 31 SRs that had pooled their data 
quantitatively. For that purpose, the approach by Bellou et al. [22] was used. For each health outcome, we calculated the number of participants and original studies involved in the MA, summary effect sizes [with 95\% confidence intervals $(\mathrm{CI})$ and $P$ values] using both random- and fixed-effects models. The 95\% prediction interval (PI) was calculated, which further accounts for between-study heterogeneity and estimates the uncertainty around the effect that would be anticipated in a new study evaluating that same association. Betweenstudy heterogeneity was measured with the $I^{2}$ statistic. An $I^{2}$ value of $50 \%$ or more is considered to represent a substantial level of heterogeneity, whereas values exceeding $75 \%$ are considered to represent considerable heterogeneity. These values also need to be interpreted in light of the size and direction of effects and the strength of the evidence for heterogeneity, based on the $P$ value from Cochran's Q test [18]. The evidence of small-study effects (i.e. the tendency of smaller studies to produce substantially larger effect size estimates compared to larger studies) was evaluated by Egger's regression asymmetry test [23]. In a more conservative way, a $P$ value less than 0.10 from Egger's test was considered to be evidence of small-study effects. Wherever possible, we extracted the estimate of the largest study (with least standard error) of each MA from a random-effect model to interpret the direction and magnitude of the effect size. We characterised the convincing associations if they met the following criteria: had significance according to a random-effects meta-analysis of less than 0.001, were based on greater than 1000 participants, had between-study heterogeneity $\left(I^{2}\right)<50 \%$ and a $95 \%$ PI excluded the null value, and had no evidence of smallstudy effects and excess significance bias. MAs where the required information was not available were excluded from mainstream analyses and presented in a separate table. The statistical analyses were done with open-source R software (version 3.3.1) for Windows using the Meta package. The Pieper et al. formula [24] was used for calculating the amount of overlap (as a percentage) of primary trials in the included SRs (i.e., corrected covered area). A corrected covered area within the range $0-5 \%$ indicates a slight overlap, $6-10 \%$ indicates a moderate overlap, $11-15 \%$ indicates a high overlap and $>15 \%$ indicates a very high amount of overlap.

\section{Results}

Our searches identified a total of 4329 records; 195 review articles met the inclusion criteria (Fig. 1). Table 1 presents the biological mechanisms of action involved. Tables 2 and 3 summarise MAs of MLT for health with and without sufficient data for quantitative synthesis,

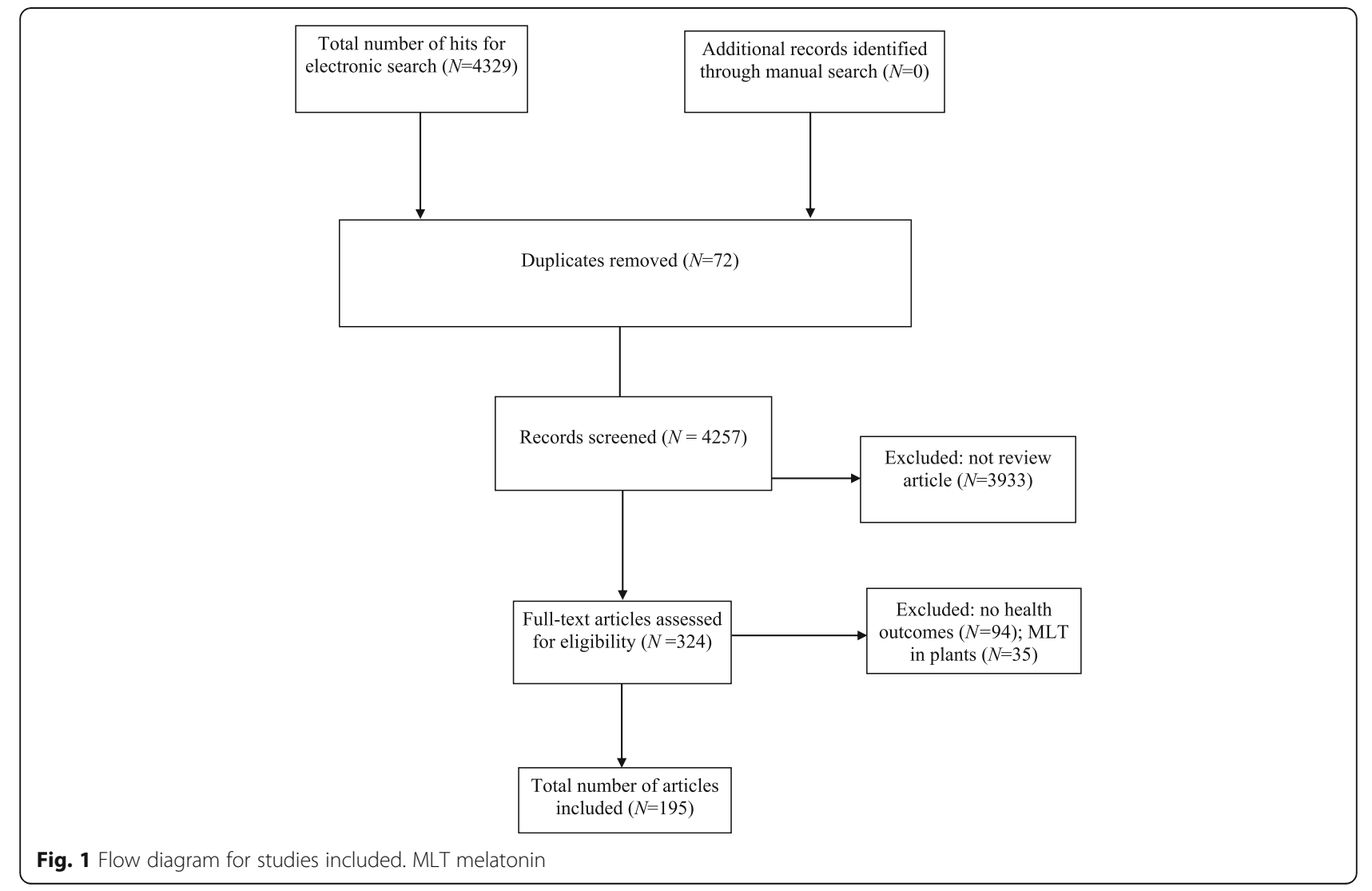


Table 1 Biological functions and processes that may be affected by MLT and suggested mechanisms of action in various models

\begin{tabular}{ll}
\hline Function or process & Effects \\
\hline Cancer & Tumour regression; activation of tumour- \\
& suppressive signalling network; oncostatic \\
& activity; modulation of oestrogen and \\
& androgen; immunomodulation or \\
& neuroimmunomodulation; cytoskeletal \\
& modulation; modulation of water transport; \\
& resynchronisation of the intracellular clock \\
& network; modulation of cellular redox status; \\
& haematopoiesis; reduced cardiotoxicity; \\
& enhanced mitochondrial function; \\
& anti-oestrogen; epigenetic regulation; \\
radioprotection
\end{tabular}

Suggested mechanisms
Reduction of cellular proliferation; free

radical scavenging; inhibition of the uptake

of linoleic acid; stimulation of glutathione

production ( $\mathrm{Y}$-glutamylcysteine synthase

and reduced reactants such as hydroxyl

radical, hydrogen peroxide, hypochlorous

acid, singlet oxygen, the peroxynitrite anion

and peroxynitrous acid); blocking cell-cycle

progression from the $\mathrm{G}$ phase to the $\mathrm{S}$

phase and by increasing p53, p21 and

p $27^{\text {Kip1 }}$ gene and protein expression

(via increased expression of E-cadherin and

B1-integrin proteins); stimulation of lymphocytes, monocytes, granulocytes, macrophages, T-helpers (Th1 and Th2), T and $B$ lymphocytes and thrombocytes;

NK cell activity; platelet generation: enhancement of the production of cytokines IL-1, IL-2, IL-4, IL-6, IL-10, IL-12,

IL-24, IFN- $\gamma$ and TNF-a; co-activation of

protein kinase $C$ and protein kinase $A$, and

phospholipase C; inhibition of angiogenesis

(via inhibition of endothelin-converting

enzyme-1 and insulin-like growth factor 1);

cell apoptosis; inhibition of $17 \beta$-oestradiol;

stimulation of biopterins; microfilament

modulation; switching microfilament

phenotypes; improving oxidative

phosphorylation and increasing ATP

generation; reduced electron leakage and

mPTP opening; decrease in gonadal

steroids; downregulation of the expression

of oestrogen a receptors; potentiation of

cytostatic anti-oestrogen sensitivity of

chemotherapeutic agents; inhibition of

DNA methyltransferase; inhibition of

telomerase; inhibition of metastasis;

mutations in the melatonin receptors

(MLT1 and MLT2); alterations of

arylalkylamine $\mathrm{N}$-acetyltransferase; reduced

thrombocytopenia; inhibition of

prostaglandin E2; inactivation of calmodulin

Metabolic and cardiovascular disorders

Anti-oxidative; anti-inflammatory; anti-hypertensive; regulation of lipid and glucose metabolism; reduction of nephrotoxicity

Neonatology and paediatrics

Anti-inflammatory; anti-oxidative; sedative

Reduction of pro-inflammatory cytokines

Protection against neurodegeneration caused by mitochondrial dysfunction and oxidative/nitrosative stress; apoptosis; prevention of vasoconstriction of cerebral arteries

Type of evidence (references)

In vitro, animal and clinical studies, RCTs,

epidemiological studies, SRs

$31,37,44,63,68,69,72-108$
Free radical scavenging; inhibition of pro-inflammatory mediator; iNOS/i-mtNOS; optimisation of nNOS/c-mtNOS; reduction of factor 1- $a$ and NF-KB; downregulation of $\mathrm{BCl}-2$ and activation of $\mathrm{p} 53$ and CD95; increase in catalase activity and reduction in thiobarbituric acid reactive substrates; reduction in lipid peroxidation, creatinine, uric acid and blood urea nitrogen levels

Free radical scavenging; inhibition of pro-inflammatory cytokines, cell adhesion molecules, NO production, COX-2 expression, NF-K activation; regulation of macrophage activity (IL-6, IL-8 and TNF-a) and nitrite/nitrate levels; inflammatory-derived activation of phospholipase A2, lipoxygenase and cyclooxygenases; increased glutathione peroxidase activity; reduction of C-reactive protein

In vitro, animal studies, placebo-controlled RCTs [80, 90, 92, 106, 109-114]

Animal studies, RCTs [50, 79-81, 92, 114, 115]

Animal and human studies, RCTs, open-label [116-119]

Activations of mitochondrial cell survival pathways; regulation of apoptosis; silencing of the Rip2/Caspase-1 pathway; reduced mitochondrial inducible $\mathrm{NO}$ synthase; increased activity of respiratory complexes I, III and IV; increased activity and expression of antioxidant enzymes; high lipophilicity
Animal and human studies, SRs $[46,49,79,81,90,94,100,106,120-124]$ 
Table 1 Biological functions and processes that may be affected by MLT and suggested mechanisms of action in various models (Continued)

\begin{tabular}{|c|c|c|c|}
\hline Function or process & Effects & Suggested mechanisms & Type of evidence (references) \\
\hline Mental disorders & $\begin{array}{l}\text { Anti-inflammatory; anti-nociceptive; } \\
\text { anxiolytic; drug detoxification }\end{array}$ & $\begin{array}{l}\text { Regulating cytokine production of } \\
\text { immunocompetent cells; reducing adhesion } \\
\text { molecules and pro-inflammatory cytokines } \\
\text { including IL-6, IL-8 and TNF; modifying serum } \\
\text { inflammatory parameters; neutralising free } \\
\text { radicals and non-radical oxygen-based } \\
\text { reactants }\end{array}$ & $\begin{array}{l}\text { Animal and human studies } \\
{[34,66,123,125-130]}\end{array}$ \\
\hline Pain syndromes & $\begin{array}{l}\text { Anti-nociceptive, antiallodynic and } \\
\text { analgesic effects; synchronisation of } \\
\text { biological rhythms }\end{array}$ & $\begin{array}{l}\text { Activation of melatoninergic MLT1/MLT2 } \\
\text { receptors; release of opioid peptides } \\
\text { ( } \beta \text {-endorphins); interaction with opioid, } \\
\text { Y-aminobutyric acid or } N \text {-methyl-daspartate } \\
\text { receptors; NO-arginine pathway; antioxidant } \\
\text { and anti-inflammatory effect; regulation of } \\
\text { endoplasmic reticulum and mitochondrial } \\
\text { activity }\end{array}$ & $\begin{array}{l}\text { Animal and human studies } \\
{[33,117,131,132]}\end{array}$ \\
\hline Reproductive functions & $\begin{array}{l}\text { Antioxidant, anti-inflammatory, } \\
\text { anti-apoptotic, cytoprotective and } \\
\text { neuroprotective effects; reduced risk of } \\
\text { complications; increased homeostasis; } \\
\text { gonadotropin secretion; higher rate of } \\
\text { mature oocytes and quality embryos }\end{array}$ & $\begin{array}{l}\text { Activation of melatoninergic MLT1/MLT2 } \\
\text { receptors; inhibition of adenyl cyclase } \\
\text { activity; forskolin-induced cAMP formation } \\
\text { with subsequent reduction in activated } \\
\text { protein kinase; alteration of granulosa cell } \\
\text { steroidogenesis and folliculogenesis; } \\
\text { corpus luteum function; inhibition of } \\
\text { prostaglandins, oxytocin, cortisol } \\
\text { production and LDL peroxidation; } \\
\text { activation of prolactin secretion; free } \\
\text { hydroxyl radicals scavenging; prevention } \\
\text { against DNA damage; activation of } \\
\text { superoxide dismutase, glutathione } \\
\text { peroxidase, glutathione reductase and } \\
\text { glucose-6-phosphate dehydrogenase; } \\
\text { inhibition of NO synthase; deferred } \\
\text { apoptosis of villous cytotrophoblasts and } \\
\text { protection of syncytiotrophoblasts; } \\
\text { improved haemodynamics and nutrient } \\
\text { transfer at the placental-uterine interface }\end{array}$ & $\begin{array}{l}\text { In vitro, animal and human studies } \\
{[62,95,115,119,133-139]}\end{array}$ \\
\hline
\end{tabular}

Sleep disorders

Traumatic CNS injury
Sleep enhancer; shifted circadian rhythms; reduced duration of jet lag

Attenuation of neural damage; neuroprotective effects; inhibition of necrosis, apoptosis; immunomodulation; protection of nuclear and mitochondrial DNA; anti-oxidative effects receptor agonist clonidine; lowered core body temperature; opening of the sleep gate and facilitation of re-entrainment to suprachiasmatic nuclei; potentiation of $\mathrm{GABA}$ on $\mathrm{GABA}_{\mathrm{A}}$ receptors; inactivation of calmodulin

Free radical scavenging (including the hydroxyl radical, hydrogen peroxide, singlet oxygen, NO, peroxynitrite anion and peroxynitrous acid); inhibition of pro-inflammatory cytokines or quinone reductase 2, calcium ion-mediated toxicity, proxidative enzymes NO synthase, lipoxygenase and phospholipase A2 activation of the tumour necrosis factor receptors; increased efficiency of oxidative phosphorylation; reduction of NF-KB or TNF expression; modulation of angiogenesis; stimulation of superoxide dismutase, glutathione peroxidase, glutathione reductase, catalase and glutathione; induction of $y$-glutamylcysteine synthetase: activation of glucose-6-phosphate dehydrogenase
RCTs $26,29,39,42,64,67,70,80,81,90$ 92, 94, 103, 105-107, 124, 140-161]

In vitro, animal and human studies $[27,32,46,61,94,106,162-168]$

ATP adenosine triphosphate, CANP cyclic adenosine monophosphate, c-mtNOS constitutive mitochondrial nitric oxide synthase, CNS central nervous system, COX-2 cyclooxygenase 2, GABA gamma-aminobutyric acid, iNOS inducible nitric oxide synthase, $i$-mtNOS inducible mitochondrial nitric oxide synthase, $L D L$ low-density lipoproteins, MLT melatonin, NF-KB nuclear factor kappa-light-chain-enhancer of activated B cells, NK natural killer, nNOS neuronal nitric oxide synthase, NO nitric oxide, MPTP mitochondrial permeability transition pore, RCT randomised controlled trial, SR systematic review, TNFa tumour necrosis factor a

respectively. Table 4 summarises reviews with overlapping conditions (Fig. 2). The key data from the included SRs or NRs are summarised in Additional file 1: Table S1 and Additional file 2: Table S2. Additional file 3: Table S3 gives the methodological quality of the papers included. Additional file 4: Table S4 lists all randomised controlled trials (RCTs) covered in the subset of 31 SRs and indicates the amount of overlap (Fig. 3). Additional file 5: Table S5 


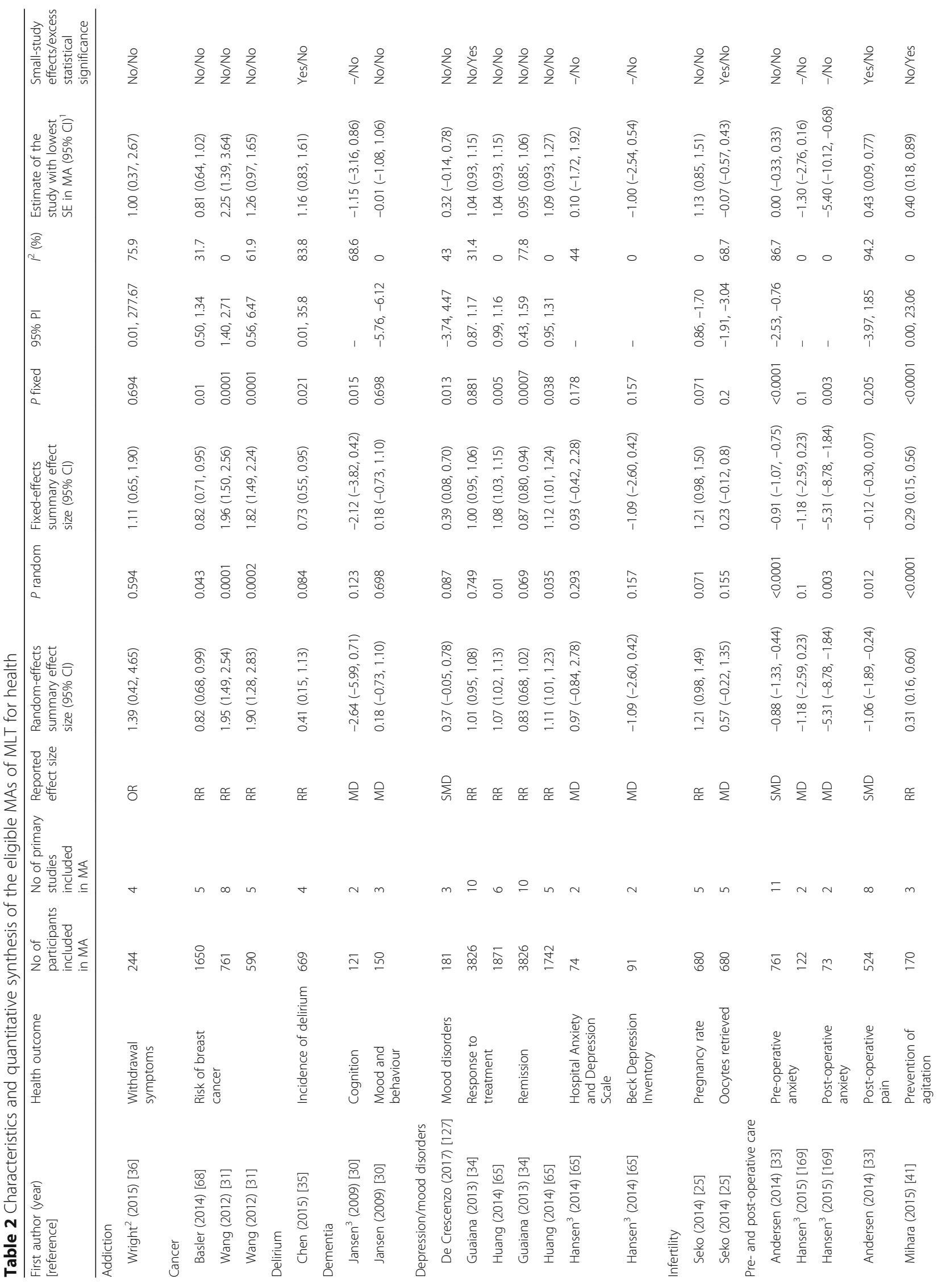


Posadzki et al. BMC Medicine (2018) 16:18

Page 7 of 18

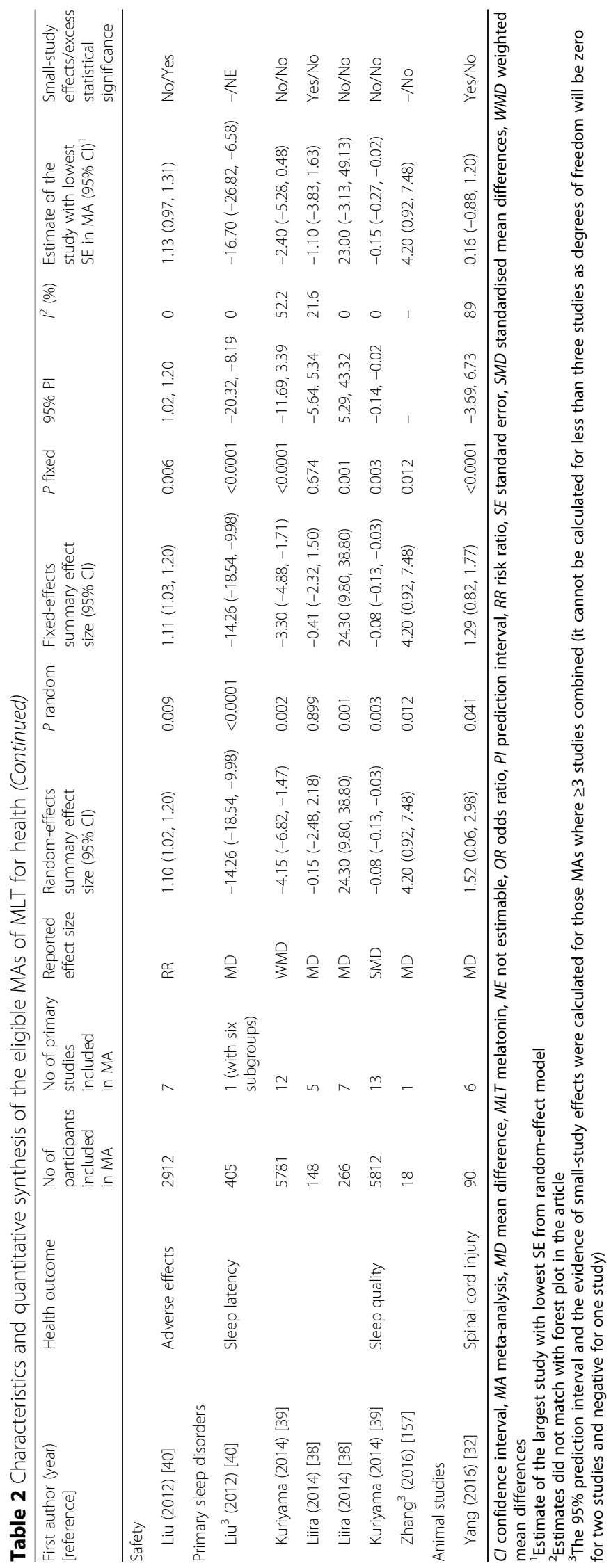


Posadzki et al. BMC Medicine (2018) 16:18

Page 8 of 18

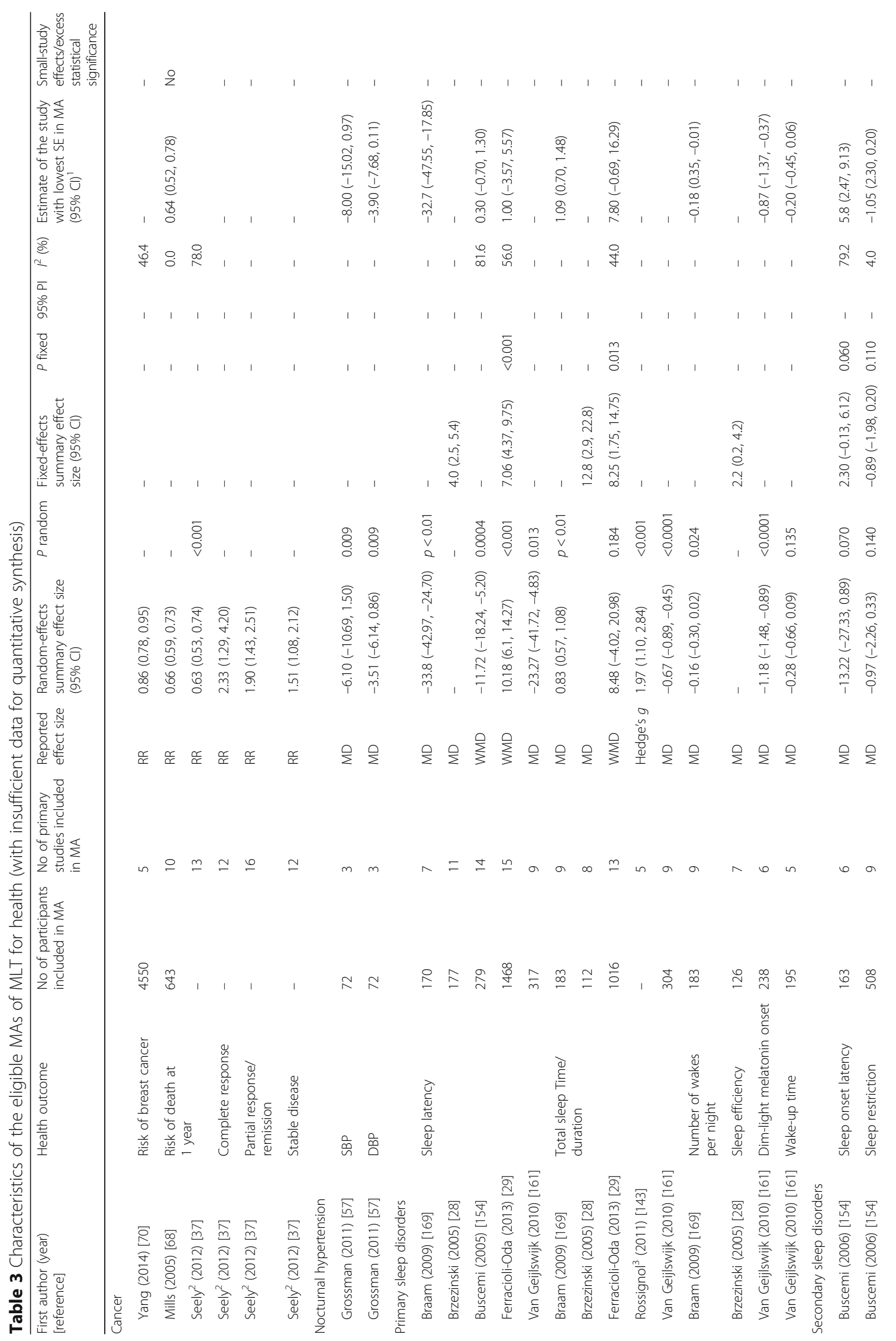




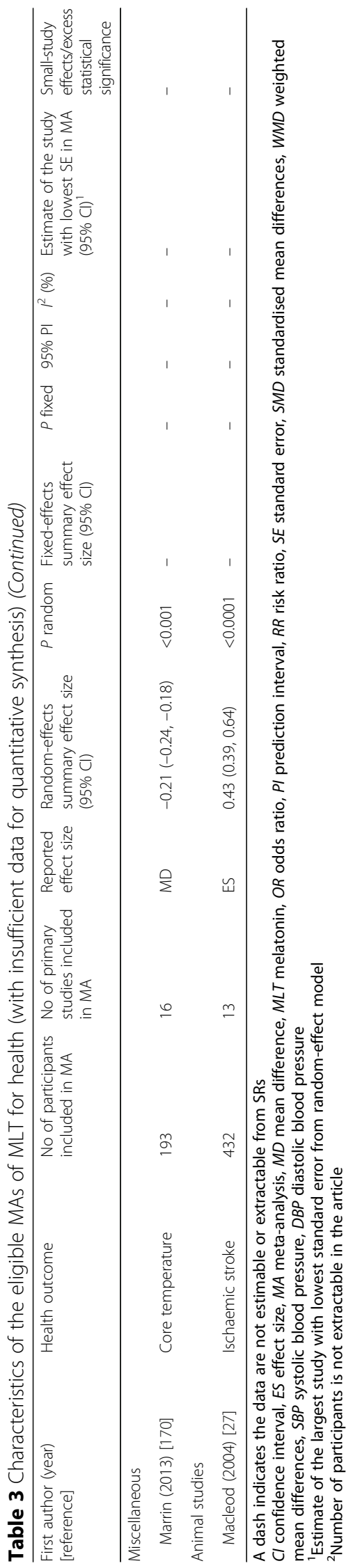


Table 4 Reviews with overlapping conditions

\begin{tabular}{ll}
\hline Subjects/condition/health outcome/indication & $\begin{array}{l}\text { Number of systematic } \\
\text { reviews }(N)\end{array}$ \\
\hline Ageing & 5 \\
Cancer & 43 \\
Cardiovascular & 9 \\
Delirium & 2 \\
Epilepsy & 2 \\
Excretory/renal functions & 2 \\
Gastrointestinal function/conditions & 7 \\
Healthy adults & 6 \\
Infections (various) & 6 \\
Inflammatory conditions & 10 \\
Menopause (symptoms) & 2 \\
Musculoskeletal system & 3 \\
Neonates, infants and children & 9 \\
(various conditions) & 37 \\
Nervous system (central and peripheral) & 18 \\
conditions/injuries & 10 \\
Neurodegenerative disorders/dementias & 10 \\
Obesity/metabolic diseases & 10 \\
Other (miscellaneous) & 6 \\
Oral cavity diseases & 3 \\
Pain syndromes & 11 \\
Pregnancy/reproductive functions/infertility & 4 \\
Pre-operative, peri-operative or post-operative & \\
care (anxiety, prevention of agitation) & \\
Protection against radiation/metal toxicity & 4 \\
Psychiatric/psychological conditions & \\
Sleep outcomes/insomnia & \\
Various clinical conditions & \\
\hline
\end{tabular}

lists adverse effects (AEs) reported in SRs. Altogether, 31 reviews were synthesised quantitatively, whereas the remaining 164 reviews were synthesised narratively.

\section{Characteristics of studies included $(N=195)$}

The number of primary studies in each SR ranged from 0 to 68 (mean $6.5 \pm 10.78$ ). The total number of participants was inestimable due to overlapping studies (optional range 61 to 5812). In 117 of the reviews (60\%), either the number of primary studies or the number of participants was not available. None of the included SRs or MAs had access to individual participant data and all relied on summary-level data from the published literature. Eighteen SRs relied on continuous data for their respective MAs [standardised mean difference (SMD), mean difference (MD) and weighted mean difference (WMD)]; and 12 (6.1\%) used dichotomous data for pooling [odds ratio (OR) and risk ratio (RR)]; with only one
MA using both types of data and analyses (RR and MD) [25]. Three MAs used effect sizes for presenting the overall estimates [26-28].

Various conditions were evaluated, ranging from acute coronary syndrome to various cancers, with insomnia/ sleep disorders being the most frequent $(N=50 ; 25.6 \%)$. Of these, 26 focused on insomnia/primary sleep disorders only, whereas the remaining 24 evaluated other health conditions with underlying (secondary) sleep disorders. Four reviews (2\%) included healthy individuals; and six (3\%) evaluated a mixture of healthy and unhealthy patients. Human studies varied from case studies $(N=4)$, case series $(N=4)$, case control $(N=2)$, cohort $(N=1)$, open-label $(N=13)$ and uncontrolled beforeafter $(N=2)$ to RCTs of parallel and cross-over design with or without the use of a placebo $(N=71)$.

Administration routes varied from oral and intravenous to sublingual; and MLT preparations included patches, pills, capsules and solutions. In total, 99 reviews (50.7\%) included animal/in vivo studies and 55 reviews (28.2\%) also included in vitro studies, whereas 84 reviews $(43 \%)$ included humans only. Confounding factors were not mentioned in 82 reviews (42\%). In the remaining 113 reviews, both exogenous and endogenous MLT levels were influenced by a range of genetic, epigenetic and environmental factors including age, gender, menopausal status, parity, oestrogen levels, lifestyle (alcohol use, body mass index, body posture, caffeine, diet, supplements, drug use, night-shift work, artificial light at night, physical activity, psychological stress and sleep hygiene) and others, including individual chronotypes, sessional variations and time, dose and route of MLT administration. In medically compromised patients, e.g. those with cancer, MLT was frequently used as an adjunct to usual care or conventional treatment such as chemotherapy, radiotherapy, supportive care and palliative care.

The most commonly cited effects of MLT were its anti-oxidative, anti-inflammatory and immunomodulatory properties (Table 1). In neoplastic diseases, the most common mechanisms of action included free radical scavenging (hydroxyl radical, hydrogen peroxide, hypochlorous acid, singlet oxygen, the peroxynitrite anion and peroxynitrous acid); stimulation of immune system; improvement of oxidative phosphorylation and ATP generation; co-activating protein kinase enzymes; reduction of cellular proliferation; inhibition of angiogenesis; prostaglandin E2 or $17 \beta$-oestradiol; the uptake of linoleic acid, DNA methyltransferase or telomerase.

\section{Evaluation of the evidence}

Four MAs [25, 29-31] had large levels of heterogeneity $\left(I^{2} \geq 50 \%\right.$ and $\left.\leq 75 \%\right)$ and six SRs [32-37] had very large levels of heterogeneity $\left(I^{2}>75 \%\right)$. The median number of studies per MA was $5(\mathrm{IQR}=4.75)$ with a median of 557 


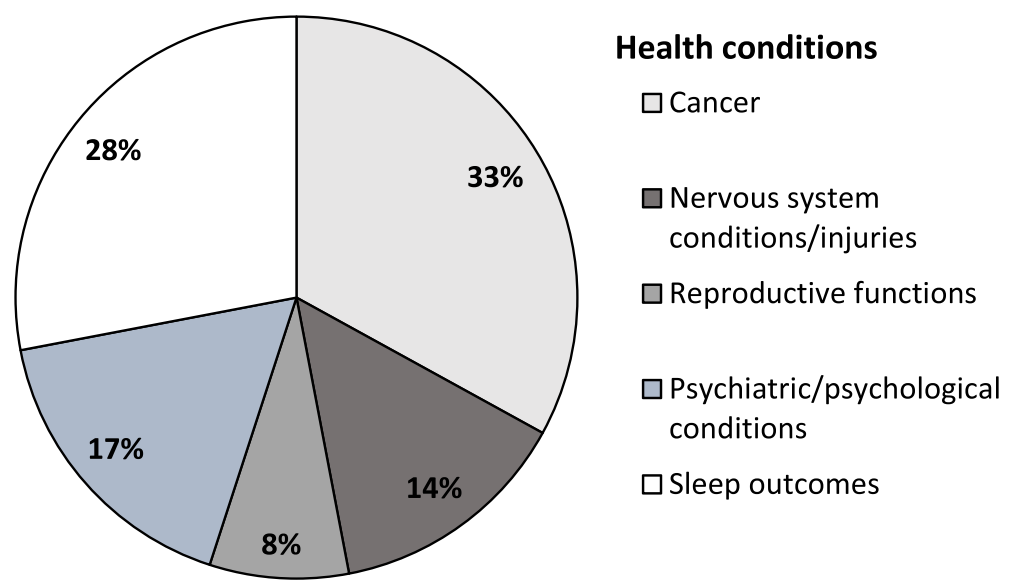

Fig. 2 Health conditions with more than ten systematic reviews

participants $(\mathrm{IQR}=1561)$. In each of the 13 MAs, more than 1000 cases were analysed. For sleep latency, preoperative anxiety, prevention of agitation or risk of breast cancer, ten (32\%) of 31 MAs reported effects that were significant at $P$ values less than 0.05 under the random-effects model, and seven (23\%) were significant at $P$ values less than 0.001 under the random-effects model [31, 33, 38-41]. For eight MAs (25.8\%), we were unable to calculate $95 \%$ PIs. The remaining 23 MAs had a 95\% PI that included the null value, meaning that, although on average MLT improves various health outcomes, this might depend on dose, duration, intensity, age, gender or underlying co-morbidities. Evidence for small-study effects was noted in three MAs (9.6\%). These MAs pertained to the incidence of delirium [35], spinal cord injury [32] or post-operative pain [33] (Table 2).

Only one review [39] for the association of MLT and sleep quality met our predefined convincing association criterion. It highlighted that ramelteon can improve sleep quality in insomnia $(\mathrm{SMD}=-0.08,95 \% \mathrm{CI}=-0.13$ to -0.03). If we reduced the minimum number of participants in an MA to $\geq 500$, then one more review [31] would satisfy the inclusion criterion. It highlighted that melatonin therapy can improve the partial and complete

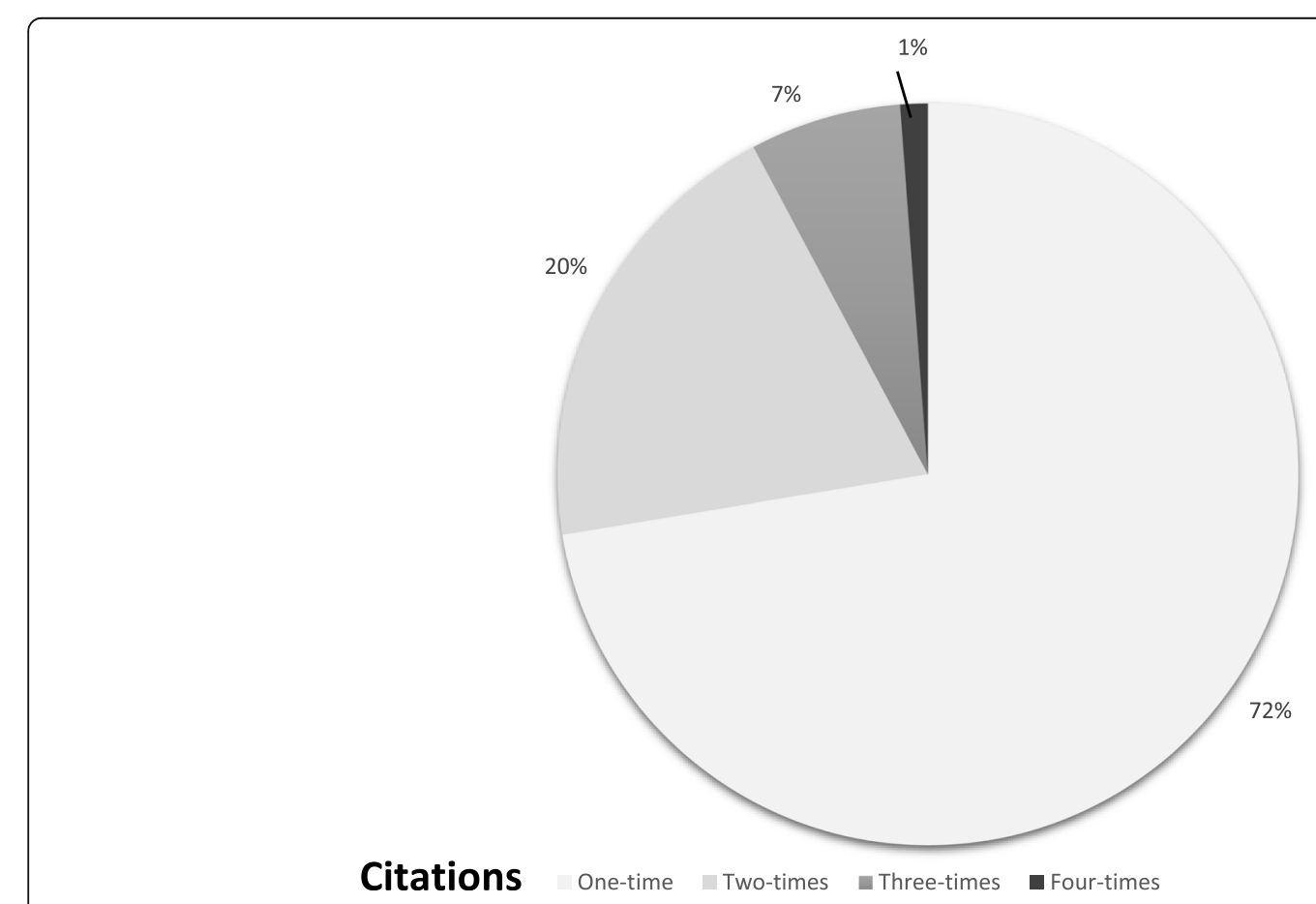

Fig. 3 Distribution of citations of different RCTs in the subset of 31 SRs and MAs included. MA meta-analysis, RCT randomised controlled trial, SR systematic review 
remission of solid tumour cancers $(\mathrm{RR}=1.95,95 \% \mathrm{CI}=$ 1.49 to 2.54 ).

\section{Quality of SRs}

The quality of the reviews as measured with the Oxman checklist was typically low (range $=-9$ to 9 ; mean $=-4.5$, $\mathrm{SD}=6.7$ ) (Additional file 3: Table S3). Of the reviews included, $153(153 / 195 ; 78.4 \%)$ did not use appropriate methods for combining studies and hence were scored as -1 .

\section{Quality (and number) of primary studies}

Altogether 154 reviews (78.9\%) did not evaluate the methodological quality of the primary studies (no validity assessments). In 41 reviews (21.1\%) that did undertake this, the methodological quality of the primary data ranged from poor $(N=5)$ to high $(N=13)$, with moderate being most commonly reported $(N=18)$, as assessed by the Cochrane Risk of Bias Tool or the Jadad Scale. The median number of primary studies included was $N=9$ (when possible to estimate).

\section{Melatonin receptor agonists}

Melatonin receptor agonists, such as Circadin (prolongedrelease MLT), ramelteon, agomelatine or tasimelteon, bind to and activate the MLT receptors 1 and 2 [42]. These analogues of MLT are believed to have the same mechanisms of action as MLT and are typically used for the treatment of sleep disorders and depression [43]. Two reviews of Circadin (prolonged-release MLT), four of ramelteon, two of agomelatine and one of tasimelteon were included. The duration, intensity and frequency varied across the reviews, with $8 \mathrm{mg}$ being most commonly used in ramelteon studies, $2 \mathrm{mg}$ for Circadin; 25-50 mg for agomelatine and 1-50 mg for tasimelteon.

\section{Endogenous vs. exogenous MLT}

In total, 31 reviews (15.8\%) evaluated both exogenous and endogenous MLT. However, it was often difficult to ascertain the number of studies looking at exogenous MLT vs. endogenous MLT only. The exogenous vs. endogenous MLT doses are also incomparable, as the routes of administration and types of studies differed considerably (optional range $0.003 \mathrm{mg}$ to $3 \mathrm{~g}$ ).

\section{Discussion}

This umbrella review aimed to summarise and critically evaluate the evidence from SRs and NRs of the effects of MLT on health and to identify the biological mechanisms of action involved. In total, 195 reviews were included (96\% of the reviews were published after 2000). Of the reviews, 99 included evidence from in vitro or animal experiments, which highlights the still experimental phase of some MLT research and the translational potential for human trials.
There was a considerable clinical and methodological heterogeneity in terms of populations evaluated (from neonates to elderly), doses, excipients, quality or purity of MLT preparations, comparators, outcome measures, study designs, lengths of follow-ups, settings, etc. Despite that, the present review does lend support to the notion that endogenous and exogenous MLT is associated with improved health outcomes. However, caution is advised for the use or supplementation of MLT in some autoimmune conditions, such as rheumatoid arthritis, asthma or organ transplantation as MLT has been reported to stimulate the function of the immune system via the production of interleukins (IL-1, IL-2, IL-6 and IL-12), interferon $\gamma$ (IFN- $\gamma$ ), $\mathrm{T}_{\mathrm{h}}$ cells, cytotoxic T cells, and B- and T-cell precursors [44].

Overall, though it seems that the connection between MLT and health is well founded, there is less evidence connecting MLT with specific diseases in a systematic way. The physiological role of MLT, as uncovered by various experimental studies, does, quite robustly, point to a direct relation between MLT and critical elements of health. However, the connection with specific conditions needs to be researched comprehensively. Thus, we suggest the need for high-quality primary data and we underline the importance of targeted studies on specific conditions, such Alzheimer's or cardiovascular diseases.

\section{Mechanisms of action}

Some of the effects of MLT are via anti-oxidative (e.g. [45-49]), anti-inflammatory (e.g. [50-52]), anti-apoptotic (e.g. [53, 54]), anti-nociceptive (e.g. [33, 55]), antihypertensive (e.g. [56-58]), cytoprotective, neuroprotective, cardioprotective or nephroprotective effects (e.g. [59-64]), and by enhancing mitochondrial function and protecting nuclear and mitochondrial DNA or regulating homeostasis (e.g. [53, 65]; Table 1). Even though some of the mechanisms of action are well established, the relative absence of the exact role of confounding factors such as diet, exercise, sleep and genetics on the role of MLT to health limits the generalisability of the results. We here identify three important factors that can be taken into account by future researchers. Firstly, the climatic conditions - and especially latitude - could bias the physiological response. Secondly, the urban environment of cities and the presence of LED light could disrupt circadian rhythms and suppress the production of MLT. Finally, the overall cultural background could also have a significant impact, as this affects nutrition and clothing.

\section{Safety}

AEs of exogenous MLT and MLT analogues were reported in 11 (5.6\%) of the included reviews. Two reviews pooled the safety data [40,66]. In Liu and Wang [40], there were more subjective reports of at least one $\mathrm{AE}$ after treatment with ramelteon compared to placebo 
( $\mathrm{RR}=1.11,1.03$ to $1.20, P<0.01$; seven studies). In Huang et al. [66], however, agomelatine revealed a lower rate of discontinuation due to AEs compared with selective serotonin reuptake inhibitors or serotonin-norepinephrine reuptake inhibitors $(\mathrm{RR}=0.38,95 \% \mathrm{CI}=0.25$ to 0.57 ). AEs were typically mild and included worsening of symptoms (seizures, asthma or headaches), transient headaches and dizziness, abdominal pain, pharyngitis, back pain and asthenia, somnolence, fatigue, nasopharyngitis, upper respiratory infection, nausea, dizziness, diarrhoea, dyspepsia, dysmenorrhoea, diarrhoea, dry mouth, increased alanine aminotransferase, nightmares, morning drowsiness, enuresis, rash and hypothermia (Additional file 5: Table S5). Given the overwhelming benefits of MLT treatment and the existence of very few and mild AEs (also for long-term use), the risk-benefit ratio favours MLT.

\section{Cost-effectiveness}

Only two reviews undertook any health economic analysis of MLT. One review stated that the cost of a 30tablet pack of $2 \mathrm{mg}$ of Circadin was $£ 15.39$ [67], whereas Liira et al. [38] 'did not find evidence on the costeffectiveness of the drugs in the included trials'. More cost-effectiveness or cost-benefit analyses would be required to confirm the economic benefits of MLT and to inform various stakeholders and policymakers.

\section{Quality (and quantity) of primary data}

In $154(78.9 \%)$ of the reviews, the quality of the primary data was not evaluated. In the 41 reviews (21\%) that did evaluate it, the quality of the primary data ranged from poor to high (average = moderate), as judged by the authors of the included reviews, primarily using the Cochrane Risk of Bias Tool. The relatively low number of primary studies (median 9) included in the SRs or NRs might be of potential concern, and signals the need for more research into a wide range of conditions and clinical areas including oncology, emergency medicine, neurology, metabolic diseases, cardiovascular medicine, gynaecology, paediatrics, psychiatry, mental health, gastrointestinal diseases and pain management.

\section{Review quality}

The methodological quality of the included SRs was frequently poor (Additional file 3: Table S3). Most of the articles that scored poorly on the Oxman checklist (quality rating scale) were NRs, which are often of poorer quality compared to SRs. As these articles do contribute relevant information, we decided to include them in our study. Of the reviews, however, 36 (18.4\%) scored 6-9 on the Oxman checklist, meaning they had minimal or no flaws.

\section{Strengths and weaknesses}

This umbrella review has important strengths, such as the inclusion and critical appraisal of 195 review articles, identification of gaps and uncertainties in the evidence base, and categorisation of significant health-related effects and associated mechanisms of action. However, this umbrella review of both SRs and NRs has several limitations that ought to be kept in mind when interpreting its results. First and foremost, even though comprehensive searches were employed, there is no guarantee that all relevant SRs of MLT were included. The searches were restricted to the past 21 years, thereby omitting some potentially older and potentially important reviews, as well as reviews published in languages other than English.

Secondly, one of the limitations of our overview is that many SRs often analysed the same primary studies. This overlap between SRs is important when interpreting results of this overview (Additional file 4: Table S4, Fig. 2). For instance, due to the double counting of the patient data resulting from the overlapping studies, the total number of patients included in our analyses is inestimable. Also, in the subset of 31 MAs, 238 RCTs were included. These RCTs were frequently used in more than one MA (range $=1-4$, mean $=1.4, \mathrm{SD}=0.66$ ), meaning that there were overlapping studies and double counting of the data (Fig. 2). To further illustrate this, three [31, 37, 68] of five MAs [31, 37, 68-70] evaluating MLT for cancers relied on the same data from the same four primary trials (Lissoni 1996, 1997, 1999, 2003). However, the amount of overlap was calculated (corrected covered area) and found to be $1.2 \%$, which is 'slight' according to Pieper's formula.

Thirdly, although, four SRs were methodologically sound (Oxman checklist score $\geq 6$ ), they were based on poor-quality primary data, which (logically) might seem contradictory.

Fourthly, we did not evaluate whether there was evidence for small-study effects using funnel plot asymmetry [23] (publication bias) because of insufficient data.

Fifthly, reviewing SRs might abandon the nuances that may be embedded in the original data, such as conflicts of interest, sources of funding, validity, generalisability etc.

Sixthly, various animal, human and in vitro models; different modes of administration; and exogenous and endogenous MLT were frequently analysed together, thereby giving limited understanding of how the results vary depending on the health outcomes evaluated.

Lastly, there is no commonly accepted cut-off point differentiating NRs vs. SRs using the Oxman scoring system. For example, a review that arbitrarily scored 2-3 on the scale (indicating the presence of major flaws) may be arbitrarily assigned as an NR as well as an SR (the definition being arbitrary too). In another example, 
reviews that could be arbitrarily judged as narrative with extensive flaws (a score of 1 or below), e.g. De Jonghe et al. [71], may include information about the number of primary studies and total sample size, i.e. 9/330. On the other hand, reviews that had no flaws (a score of 6-9) may not have that information, e.g. Liira et al. [38]. Taken together, these limitations reduce the conclusiveness of our findings, making them prone to criticism.

\section{Conclusions}

Despite the abundance of evidence, more systematic research is needed to understand and establish the connection between MLT and specific aspects of health, potentially as a function of important lifestyle choices.

\section{Additional files}

Additional file 1: Table S1. Summary of studies on the effects of exogenous melatonin on health outcomes $(N=120)$. (DOCX $174 \mathrm{~kb})$

Additional file 2: Table S2. Summary of studies on the effects of endogenous melatonin on health outcomes $(N=75)$. (DOCX $111 \mathrm{~kb})$

Additional file 3: Table S3. Quality ratings for included systematic reviews of melatonin for health. (DOCX $254 \mathrm{~kb}$ )

Additional file 4: Table S4. List of randomised trials covered in the systematic reviews. (DOCX $58 \mathrm{~kb}$ )

Additional file 5: Table S5. Summary of the adverse effects of MLT reported in the studies included $(N=11)$. (DOCX $24 \mathrm{~kb})$

\section{Appendix}

The search strategy for MEDLINE (via Ovid)

1. Melatonin.mp.

2. exp Melatonin/

3. urinary 6-sulfatoxymelatonin.mp.

4. $1-3 /$ or

5. Health.mp.

6. exp Health/

7. 5-6/or

8. Review.ti,ab.

9. 4. AND 7 AND 8

\section{Abbreviations}

AE: Adverse effect; Cl: confidence interval; DNA: Deoxyribonucleic acid; LED: Light-emitting diode; MA: Meta-analysis; MD: Mean difference; MLT: Melatonin; NR: Narrative review; OR: Odds ratio; PI: Prediction interval; PRISMA: Preferred Reporting Items for Systematic Reviews and Meta-Analyses; RCT: Randomised controlled trial; RR: Risk ratio; SD: Standard deviation; SMD: Standardised mean difference; SR: Systematic review; WMD: Weighted mean difference

\section{Acknowledgements}

We gratefully acknowledge Professor Kian Woon Kwok for his invaluable comments and suggestions when writing and revising the manuscript.

\section{Funding}

This material is based on research and work supported by award L2NICCFP1-2013-2 to principal investigator CKS from the Land and Liveability National Innovation Challenge (L2 NIC)). Any opinions, findings, conclusions or recommendations expressed in this material are those of the author(s) and do not necessarily reflect the views of L2 NIC.

\section{Availability of data and materials}

No additional data are available.

\section{Authors' contributions}

JC and PP conceived of the idea for the review. PP wrote the protocol, ran the searches, screened, extracted, analysed and synthesised data, and wrote and revised the drafts. BMK, GD, SB and UD screened and extracted the data. RB analysed the data. AB, KJ, GIC, CKS, NEEK, NJR, MS and JC critically revised the manuscript, interpreted the data for the work, approved the final version of the paper and agreed to be accountable for all aspects of the work. All authors contributed to writing and reviewing the manuscript. PP is the guarantor. All authors read and approved the final manuscript.

\section{Ethics approval}

Not needed.

\section{Consent for publication}

Not applicable.

\section{Competing interests}

All authors have completed the International Committee of Medical Journal Editors uniform disclosure form at www.icmje.org/coi_disclosure.pdf (available on request from the corresponding author) and declare that they have no competing interests.

\section{Publisher's Note}

Springer Nature remains neutral with regard to jurisdictional claims in published maps and institutional affiliations.

\section{Author details}

${ }^{1}$ Centre for Population Health Sciences, 11 Mandalay Road, Level 18 Clinical Sciences Building, Lee Kong Chian School of Medicine, Novena Campus, Nanyang Technological University, Singapore 308232, Singapore. ${ }^{2}$ School of Health and Life Sciences, Glasgow Caledonian University, Glasgow G4 OBA, UK. ${ }^{3}$ The Hebrew University Medical School, Hadassah Hebrew University Medical Center, 91120 Jerusalem, Israel. ${ }^{4}$ Nanyang Business School, Division of Strategy Management and Organisation, Nanyang Technological University, Singapore 639798, Singapore. ${ }^{5}$ School of Civil and Environmental Engineering, College of Engineering, Nanyang Technological University, Singapore 639798, Singapore. ${ }^{6} \mathrm{Global}$ eHealth Unit, School of Public Health, Imperial College London, London W6 8RP, UK.

Received: 16 August 2017 Accepted: 20 December 2017 Published online: 05 February 2018

\section{References}

1. Edgar RS, Green EW, Zhao Y, van Ooijen G, Olmedo M, Qin X, et al. Peroxiredoxins are conserved markers of circadian rhythms. Nature. 2012;485(7399):459-64.

2. $\mathrm{Wu} \mathrm{AH}$, et al. Sleep duration, melatonin and breast cancer among Chinese women in Singapore. Carcinogenesis. 2008;29(6):1244-8.

3. Arendt J. Melatonin, circadian rhythms, and sleep. N Engl J Med. 2000;343(15):1114-16.

4. Mirick DK, Davis S. Melatonin as a biomarker of circadian dysregulation. Cancer Epidemiol. 2008;17(12):3306-13.

5. Brzezinski A. Melatonin in humans. N Engl J Med. 1997:336(3):186-95.

6. Eisenstein M. Chronobiology: stepping out of time. Nature. 2013:497(7450 SUPPL):S10-12

7. Bass J, Takahashi JS. Circadian integration of metabolism and energetics. Science. 2010;330(6009):1349-54

8. Boyce P, Barriball E. Circadian rhythms and depression. Aust Family Physician. 2010;39(5):307-10.

9. Mea F. Vitamin D, status and PTH in young men: a cross-sectional study on associations with bone mineral density, body composition and glucose metabolism. Clin Endocrinol. 2010;73(5):573-80.

10. Haus E, Smolensky M. Biological clocks and shift work: circadian dysregulation and potential long-term effects. Cancer Causes Control. 2006;17(4):489-500. 
11. Kvaskoff M, Weinstein P. Are some melanomas caused by artificial light? Med Hypothesises. 2010;75(3):305-11.

12. Mahoney MM. Shift work, jet lag, and female reproduction. Int J Endocrinol. 2010;2010:9. Article ID 813764. https://doi.org/10.1155/2010/813764.

13. Rana S, Mahmood S. Circadian rhythm and its role in malignancy. J Circadian Rhythms. 2010;8(3):1-13.

14. Bass J, Lazar MA. Circadian time signatures of fitness and disease. Science. 2016;354(6315):994-9.

15. Bonmati-Carrion MA, Arguelles-Prieto R, Martinez-Madrid MJ, Reiter R, Hardeland R, Rol MA, et al. Protecting the melatonin rhythm through circadian healthy light exposure. Int J Mol Sci. 2014;15(12):23448-500.

16. Schlafer $\mathrm{O}$, Wenzel $V$, Hogl B. Sleep disorders among physicians on shift work. Anaesthetist. 2014;63(11):844-51.

17. Scholtens RM, van Munster BC, van Kempen MF, de Rooij SEJA. Physiological melatonin levels in healthy older people: a systematic review. J Psychosom Res. 2016;86:20-7.

18. Higgins J, Green S, editors. Cochrane handbook for systematic reviews of interventions, version 5.1 .0 (updated March 2011). The Cochrane Collaboration. 2011. http://handbook-5-1.cochrane.org/.

19. Posadzki P, Ernst E. Systematic reviews of spinal manipulations for headaches: an attempt to clear up the confusion. Headache. 2011; 51(9):1419-25.

20. Pae $\mathrm{C}-\mathrm{U}$. Why systematic review rather than narrative review? Psychiatry Invest. 2015;12(3):417-19.

21. Oxman $A D$, Guyatt $G H$. Validation of an index of the quality of review articles. J Clin Epidemiol. 1991;44(11):1271-8.

22. Bellou V, Belbasis L, Tzoulaki I, Evangelou E, loannidis JP. Environmental risk factors and Parkinson's disease: an umbrella review of meta-analyses. Parkinsonism Relat Disord. 2016;23:1-9.

23. Egger M, Davey Smith G, Schneider M, Minder C. Bias in meta-analysis detected by a simple, graphical test. BMJ. 1997;315(7109):629-34.

24. Pieper D, Antoine SL, Mathes T, Neugebauer EA, Eikermann M. Systematic review finds overlapping reviews were not mentioned in every other overview. J Clin Epidemiol. 2014;67(4):368-75.

25. Seko LM, Moroni RM, Leitao VM, Teixeira DM, Nastri CO, Martins WP. Melatonin supplementation during controlled ovarian stimulation for women undergoing assisted reproductive technology: systematic review and meta-analysis of randomized controlled trials. Fertil Steril. 2014;101(1):154-61.

26. Winkler A, Auer C, Doering BK, Rief W. Drug treatment of primary insomnia: a meta-analysis of polysomnographic randomized controlled trials. CNS Drugs. 2014;28(9):799-816.

27. Macleod MR, O'Collins T, Horky LL, Howells DW, Donnan GA. Systematic review and meta-analysis of the efficacy of melatonin in experimental stroke. J Pineal Res. 2005;38(1):35-41.

28. Brzezinski A, Vangel MG, Wurtman RJ, Norrie G, Zhdanova I, Ben-Shushan A, et al. Effects of exogenous melatonin on sleep: a meta-analysis. Sleep Med Rev. 2005;9(1):41-50

29. Ferracioli-Oda E, Qawasmi A, Bloch MH. Meta-analysis: melatonin for the treatment of primary sleep disorders. PLoS One. 2013;8(5):e63773.

30. Jansen SL, Forbes DA, Duncan V, Morgan DG. Melatonin for cognitive impairment. Cochrane Database Syst Rev. 2006;(1):CD003802.

31. Wang YM, Jin BZ, Ai F, Duan CH, Lu YZ, Dong TF, et al. The efficacy and safety of melatonin in concurrent chemotherapy or radiotherapy for solid tumors: a meta-analysis of randomized controlled trials. Cancer Chemother Pharmacol. 2012;69(5):1213-20.

32. Yang L, Yao M, Lan Y, Mo W, Sun YL, Wang J, et al. Melatonin for spinal cord injury in animal models: a systematic review and network meta-analysis. J Neurotrauma. 2016;33(3):290-300.

33. Andersen LP, Werner MU, Rosenberg J, Gogenur I. A systematic review of peri-operative melatonin. Anaesthesia. 2014;69(10):1163-71.

34. Guaiana G, Gupta S, Chiodo D, Davies SJ, Haederle K, Koesters M. Agomelatine versus other antidepressive agents for major depression. Cochrane Database Syst Rev. 2013;(12):CD008851.

35. Chen S, Shi L, Liang F, Xu L, Desislava D, Wu Q, et al. Exogenous melatonin for delirium prevention: a meta-analysis of randomized controlled trials. Mol Neurobiol. 2016;53(6):4046-53.

36. Wright A, Diebold J, Otal J, Stoneman C, Wong J, Wallace C, et al. The effect of melatonin on benzodiazepine discontinuation and sleep quality in adults attempting to discontinue benzodiazepines: a systematic review and meta-analysis. Drugs Aging. 2015;32(12):1009-18.
37. Seely D, Wu P, Fritz H, Kennedy DA, Tsui T, Seely AJ, et al. Melatonin as adjuvant cancer care with and without chemotherapy: a systematic review and meta-analysis of randomized trials. Integr Cancer Ther. 2012; 11(4):293-303.

38. Liira J, Verbeek JH, Costa G, Driscoll TR, Sallinen M, Isotalo LK, et al. Pharmacological interventions for sleepiness and sleep disturbances caused by shift work. Cochrane Database Syst Rev. 2014;(8):CD009776.

39. Kuriyama A, Honda M, Hayashino Y. Ramelteon for the treatment of insomnia in adults: a systematic review and meta-analysis. Sleep Med. 2014;15(4):385-92.

40. Liu J, Wang LN. Ramelteon in the treatment of chronic insomnia: systematic review and meta-analysis. Int J Clin Pract. 2012;66(9):867-73.

41. Mihara T, Nakamura N, Ka K, Oba MS, Goto T. Effects of melatonin premedication to prevent emergence agitation after general anaesthesia in children: a systematic review and meta-analysis with trial sequential analysis. Eur J Anaesthesiol. 2015;32(12):862-71.

42. Leger D, Quera-Salva MA, Vecchierini MF, Ogrizek P, Perry CA, Dressman MA Safety profile of tasimelteon, a melatonin MT1 and MT2 receptor agonist: pooled safety analyses from six clinical studies. Expert Opin Drug Saf. 2015;14(11):1673-85.

43. Pandi-Perumal SR, Trakht I, Srinivasan V, Spence DW, Maestroni GJ, Zisapel N, et al. Physiological effects of melatonin: role of melatonin receptors and signal transduction pathways. Prog Neurobiol. 2008;85(3):335-53.

44. Carrillo-Vico A, Guerrero JM, Lardone PJ, Reiter RJ. A review of the multiple actions of melatonin on the immune system. Endocrine. 2005; 27(2):189-200.

45. Reiter RJ, Tan DX, Osuna C, Gitto E. Actions of melatonin in the reduction of oxidative stress. A review. J Biomed Sci. 2000;7(6):444-58.

46. Reiter RJ, Tan DX, Qi W, Manchester LC, Karbownik M, Calvo JR. Pharmacology and physiology of melatonin in the reduction of oxidative stress in vivo. Biol Signals Recept. 2000;9(3-4):160-71.

47. Maldonado MD, Murillo-Cabezas F, Calvo JR, Lardone PJ, Tan DX, Guerrero JM, Reiter RJ. Melatonin as pharmacologic support in burn patients: a proposed solution to thermal injury-related lymphocytopenia and oxidative damage. Crit Care Med. 2007;35(4):1177-85.

48. Vielma JR, Bonilla E, Chacin-Bonilla L, Mora M, Medina-Leendertz S, Bravo Y. Effects of melatonin on oxidative stress, and resistance to bacterial, parasitic, and viral infections: a review. Acta Trop. 2014;137:31-8.

49. Reiter RJ, Tan DX, Pappolla MA. Melatonin relieves the neural oxidative burden that contributes to dementias. Ann NY Acad Sci. 2004;1035(1):179-96.

50. Terry PD, Villinger F, Bubenik GA, Sitaraman SV. Melatonin and ulcerative colitis: evidence, biological mechanisms, and future research. Inflamm Bowel Dis. 2009;15(1):134-40.

51. Hardeland R, Cardinali DP, Brown GM, Pandi-Perumal SR. Melatonin and brain inflammaging. Prog Neurobiol. 2015;127-128 Suppl.(C):46-63.

52. Jena G, Trivedi PP. A review of the Uue of melatonin in ulcerative colitis: experimental evidence and new approaches. Inflamm Bowel Dis. 2014;20(3):553-63.

53. Hosseinzadeh A, Kamrava SK, Joghataei MT, Darabi R, Shakeri-Zadeh A, Shahriari $M$, et al. Apoptosis signaling pathways in osteoarthritis and possible protective role of melatonin. J Pineal Res. 2016:61(4):411-25.

54. Wang $X$. The antiapoptotic activity of melatonin in neurodegenerative diseases. CNS Neurosci Ther. 2009:15(4):345-57.

55. Srinivasan V, Lauterbach EC, Ho KY, Acuña-Castroviejo D, Zakaria R, Brzezinski A. Melatonin in antinociception: its therapeutic applications. Curr Neuropharmacol. 2012;10(2):167-78.

56. Beyer CE, Steketee JD, Saphier D. Antioxidant properties of melatonin - an emerging mystery. Biochem Pharmacol. 1998;56(10):1265-72.

57. Grossman E, Laudon M, Zisapel N. Effect of melatonin on nocturnal blood pressure: meta-analysis of randomized controlled trials. Vasc Health Risk Manag. 2011;7:577-84

58. Tain YL, Huang LT, Hsu CN. Developmental programming of adult disease: reprogramming by melatonin? Int J Mol Sci. 2017;18(2):16.

59. Mayo JC, Sainz RM, González Menéndez P, Cepas V, Tan DX, Reiter RJ. Melatonin and sirtuins: a 'not-so unexpected' relationship. J Pineal Res. 2017;62(2):1-17.

60. Biran V, Phan Duy A, Decobert F, Bednarek N, Alberti C, Baud O. Is melatonin ready to be used in preterm infants as a neuroprotectant? Dev Med Child Neurol. 2014;56(8):717-23.

61. Cheung RT. The utility of melatonin in reducing cerebral damage resulting from ischemia and reperfusion. J Pineal Res. 2003;34(3):153-60. 
62. Wilkinson D, Shepherd E, Wallace EM. Melatonin for women in pregnancy for neuroprotection of the fetus. Cochrane Database Syst Rev. 2016;3: CD010527.

63. Govender J, Loos B, Marais E, Engelbrecht AM. Mitochondrial catastrophe during doxorubicin-induced cardiotoxicity: a review of the protective role of melatonin. J Pineal Res. 2014;57(4):367-80.

64. Yang $Y$, Sun Y, Yi W, Li Y, Fan C, Xin Z, et al. A review of melatonin as a suitable antioxidant against myocardial ischemia-reperfusion injury and clinical heart diseases. J Pineal Res. 2014;57(4):357-66.

65. Ramos E, Patino P, Reiter RJ, Gil-Martin E, Marco-Contelles J, Parada E, et al. Ischemic brain injury: new insights on the protective role of melatonin. Free Radic Biol Med. 2017;104:32-53.

66. Huang KL, Lu WC, Wang YY, Hu GC, Lu CH, Lee WY, et al. Comparison of agomelatine and selective serotonin reuptake inhibitors/serotonin-norepinephrine reuptake inhibitors in major depressive disorder: a meta-analysis of head-to-head randomized clinical trials. Aust NZ J Psychiatry. 2014;48(7):663-71.

67. Farez MF, Mascanfroni ID, Méndez-Huergo SP, Yeste A, Murugaiyan G, Garo LP, et al. Melatonin contributes to the seasonality of multiple sclerosis relapses. Cell. 2015;162(6):1338-52.

68. Mills E, Wu P, Seely D, Guyatt G. Melatonin in the treatment of cancer: a systematic review of randomized controlled trials and meta-analysis. J Pineal Res. 2005;39(4):360-6.

69. Basler M, Jetter A, Fink D, Seifert B, Kullak-Ublick GA, Trojan A. Urinary excretion of melatonin and association with breast cancer: meta-analysis and review of the literature. Breast Care. 2014;9(3):182-7.

70. Yang WS, Deng Q, Fan WY, Wang WY, Wang X. Light exposure at night, sleep duration, melatonin, and breast cancer: a dose-response analysis of observational studies. Eur J Cancer Prev. 2014;23(4):269-76.

71. De Jonghe A, Korevaar JC, Van Munster BC, De Rooij SE. Effectiveness of melatonin treatment on circadian rhythm disturbances in dementia. Are there implications for delirium? A systematic review. Int J Geriatric Psychiatry. 2010;25(12):1201-8.

72. Rondanelli M, Faliva MA, Perna S, Antoniello N. Update on the role of melatonin in the prevention of cancer tumorigenesis and in the management of cancer correlates, such as sleep-wake and mood disturbances: review and remarks. Aging Clin Exp Res. 2013;25(5):499-510.

73. Shiu SYW. Towards rational and evidence-based use of melatonin in prostate cancer prevention and treatment. J Pineal Res. 2007;43(1):1-9.

74. Xin Z, Jiang $S$, Jiang $P$, Yan $X$, Fan C, Di S, et al. Melatonin as a treatment for gastrointestinal cancer: a review. J Pineal Res. 2015;58(4):375-87.

75. Mehta A, Kaur G. Potential role of melatonin in prevention and treatment of oral carcinoma. Indian J Dent. 2014;5(2):86-91.

76. Bartsch $\mathrm{C}$, Bartsch $\mathrm{H}$. The anti-tumor activity of pineal melatonin and cancer enhancing life styles in industrialized societies. Cancer Causes Control. 2006;17(4):559-71.

77. Benitez-King G, Soto-Vega E, Ramirez-Rodriguez G. Melatonin modulates microfilament phenotypes in epithelial cells: implications for adhesion and inhibition of cancer cell migration. Histol Histopathol. 2009;24(6):789-99.

78. Bizzarri M, Proietti S, Cucina A, Reiter RJ. Molecular mechanisms of the pro-apoptotic actions of melatonin in cancer: a review. Expert Opin Ther Targets. 2013:17(12):1483-96.

79. Bonnefont-Rousselot D, Collin F. Melatonin: action as antioxidant and potential applications in human disease and aging. Toxicology. 2010;278(1):55-67.

80. Bubenik GA, Blask DE, Brown GM, Maestroni GJ, Pang SF, Reiter RJ, et al. Prospects of the clinical utilization of melatonin. Biol Signals Recept. 1998;7(4):195-219.

81. Carpentieri A, Diaz de Barboza G, Areco V, Peralta Lopez M, Tolosa de Talamoni N. New perspectives in melatonin uses. Pharmacol Res. 2012;65(4):437-44.

82. Cos S, Sanchez-Barcelo EJ. Melatonin, experimental basis for a possible application in breast cancer prevention and treatment. Histol Histopathol. 2000;15(2):637-47

83. Cutando A, Aneiros-Fernandez J, Aneiros-Cachaza J, Arias-Santiago S. Melatonin and cancer: current knowledge and its application to oral cavity tumours. J Oral Pathol Med. 2011;40(8):593-7.

84. Di Bella L, Gualano L. Key aspects of melatonin physiology: thirty years of research. Neuro Endocrinol Lett. 2006:27(4):425-32.

85. Dopfel RP, Schulmeister K, Schernhammer ES. Nutritional and lifestyle correlates of the cancer-protective hormone melatonin. Cancer Detect Prev. 2007;31(2):140-8.

86. Dziegiel P, Podhorska-Okolow M, Zabel M. Melatonin: adjuvant therapy of malignant tumors. Med Sci Monit. 2008;14(5):Ra64-70.
87. Giannoulia-Karantana A, Vlachou A, Polychronopoulou S, Papassotiriou I, Chrousos GP. Melatonin and immunomodulation: connections and potential clinical applications. Neuroimmunomodulation. 2006;13(3):133-44.

88. Hill SM, Belancio VP, Dauchy RT, Xiang S, Brimer S, Mao L, et al. Melatonin: an inhibitor of breast cancer. Endocr Relat Cancer. 2015;22(3):R183-204.

89. Jung B, Ahmad N. Melatonin in cancer management: progress and promise. Cancer Res. 2006;66(20):9789-93.

90. Karaaslan C, Suzen S. Antioxidant properties of melatonin and its potential action in diseases. Curr Top Med Chem. 2015;15(9):894-903.

91. Ma Z, Yang Y, Fan C, Han J, Wang D, Di S, et al. Melatonin as a potential anticarcinogen for non-small-cell lung cancer. Oncotarget. 2016;7(29):46768-84.

92. Malhotra S, Sawhney G, Pandhi P. The therapeutic potential of melatonin: a review of the science. MedGenMed. 2004;6(2):46.

93. Panzer A, Viljoen M. The validity of melatonin as an oncostatic agent. J Pineal Res. 1997:22(4):184-202.

94. Reiter RJ. Melatonin: clinical relevance. Best Pract Res Clin Endocrinol Metab. 2003:17(2):273-85

95. Sanchez-Barcelo EJ, Cos S, Mediavilla D, Martinez-Campa C, Gonzalez A, Alonso-Gonzalez C. Melatonin-estrogen interactions in breast cancer. J Pineal Res. 2005;38(4):217-22.

96. Sanchez-Barcelo EJ, Mediavilla MD, Alonso-Gonzalez C, Reiter RJ. Melatonin uses in oncology: breast cancer prevention and reduction of the side effects of chemotherapy and radiation. Expert Opin Investig Drugs. 2012;21(6):819-31.

97. Shirazi A, Ghobadi G, Ghazi-Khansari M. A radiobiological review on melatonin: a novel radioprotector. J Radiat Res. 2007;48(4):263-72.

98. Vijayalaxmi Reiter RJ, Tan DX, Herman TS, Thomas Jr CR. Melatonin as a radioprotective agent: a review. Int J Radiat Oncol Biol Phys. 2004;59(3):639-53.

99. Cutando A, Lopez-Valverde A, de Vicente J, Gimenez JL, Carcia IA, de Diego RG. Action of melatonin on squamous cell carcinoma and other tumors of the oral cavity. Oncol Lett. 2014;7(4):923-6.

100. Reiter RJ, Tan DX, Manchester LC, Qi W. Biochemical reactivity of melatonin with reactive oxygen and nitrogen species: a review of the evidence. Cell Biochem Biophys. 2001;34(2):237-56.

101. Chen CQ, Fichna J, Bashashati M, Li YY, Storr M. Distribution, function and physiological role of melatonin in the lower gut. World J Gastroenterol. 2011:17(34):3888-98.

102. Jung-Hynes B, Reiter RJ, Ahmad N. Sirtuins, melatonin and circadian rhythms: building a bridge between aging and cancer. J Pineal Res. 2010;48(1):9-19.

103. Brzezinski A. 'Melatonin replacement therapy' for postmenopausal women: is it justified? Menopause. 1998;5(1):60-4.

104. Blask DE, Hill SM, Dauchy RT, Xiang S, Yuan L, Duplessis T, et al. Circadian regulation of molecular, dietary, and metabolic signaling mechanisms of human breast cancer growth by the nocturnal melatonin signal and the consequences of its disruption by light at night. J Pineal Res. 2011;51(3):259-69.

105. Nowak JZ, Zawilska JB. Melatonin and its physiological and therapeutic properties. Pharm World Sci. 1998;20(1):18-27.

106. Paul R, Borah A. The potential physiological crosstalk and interrelationship between two sovereign endogenous amines, melatonin and homocysteine. Life Sci. 2015;139:97-107.

107. Pandi-Perumal SR, Trakht I, Spence DW, Srinivasan V, Dagan Y, Cardinali DP. The roles of melatonin and light in the pathophysiology and treatment of circadian rhythm sleep disorders. Nat Clin Pract Neurol. 2008;4(8):436-47.

108. Su SC, Hsieh MJ, Yang WE, Chung WH, Reiter RJ, Yang SF. Cancer metastasis: mechanisms of inhibition by melatonin. J Pineal Res. 2017;62(1):1-11.

109. Rodríguez AD. Melatonin in the acute coronary syndromes. Salud(i)Ciencia. 2007;15(6):983-5.

110. Chang YS, Lin MH, Lee JH, Lee PL, Dai YS, Chu KH, et al. Melatonin supplementation for children with atopic dermatitis and sleep disturbance: a randomized clinical trial. JAMA Pediatr. 2016;170(1):35-42.

111. Favero G, Rodella LF, Reiter RJ, Rezzani R. Melatonin and its atheroprotective effects: a review. Mol Cell Endocrinol. 2014;382(2):926-37.

112. Hrenak J, Paulis L, Repova K, Aziriova S, Nagtegaal EJ, Reiter RJ, et al. Melatonin and renal protection: novel perspectives from animal experiments and human studies (review). Curr Pharm Des. 2015;21(7):936-49.

113. Nduhirabandi F, du Toit EF, Lochner A. Melatonin and the metabolic syndrome: a tool for effective therapy in obesity-associated abnormalities? Acta Physiol. 2012;205(2):209-23. 
114. Reiter RJ, Rosales-Corral SA, Manchester LC, Liu X, Tan DX. Melatonin in the biliary tract and liver: health implications. Curr Pharm Des. 2014;20(30):4788-801.

115. Reiter RJ, Tan DX, Tamura H, Cruz MH, Fuentes-Broto L. Clinical relevance of melatonin in ovarian and placental physiology: a review. Gynecol Endocrinol. 2014;30(2):83-9.

116. Chen YC, Tain YL, Sheen JM, Huang LT. Melatonin utility in neonates and children. J Formos Med Assoc. 2012;111(2):57-66.

117. Srinivasan $V$, Mohamed $M$, Kato $H$. Melatonin in bacterial and viral infections with focus on sepsis: a review. Recent Pat Endocr Metab Immune Drug Discov. 2012;6(1):30-9.

118. Aversa S, Pellegrino S, Barberi I, Reiter RJ, Gitto E. Potential utility of melatonin as an antioxidant during pregnancy and in the perinatal period. J Matern Fetal Neonatal Med. 2012;25(3):207-21.

119. Marseglia L, D'Angelo G, Manti S, Reiter RJ, Gitto E. Potential utility of melatonin in preeclampsia, intrauterine fetal growth retardation, and perinatal asphyxia. Reprod Sci. 2016:23(8):970-7.

120. Ramis MR, Esteban S, Miralles A, Tan DX, Reiter RJ. Protective effects of melatonin and mitochondria-targeted antioxidants against oxidative stress: a review. Curr Med Chem. 2015;22(22):2690-711.

121. Romero A, Ramos E, de Los Rios C, Egea J, Del Pino J, Reiter RJ. A review of metal-catalyzed molecular damage: protection by melatonin. J Pineal Res. 2014;56(4):343-70.

122. Jemima J, Bhattacharjee $P$, Singhal RS. Melatonin - a review on the lesser known potential nutraceutical. Int J Pharm Sci Res. 2011;2(8):1975-87.

123. Reiter RJ, Benitez-King G. Melatonin reduces neuronal loss and cytoskeletal deterioration: implications for psychiatry. Salud Mental. 2009;32(1):3-11.

124. Xu J, Wang LL, Dammer EB, Li CB, Xu G, Chen SD, et al. Melatonin for sleep disorders and cognition in dementia: a meta-analysis of randomized controlled trials. Am J Alzheimers Dis Other Demen. 2015;30(5):439-47.

125. Pacchierotti C, lapichino S, Bossini L, Pieraccini F, Castrogiovanni $P$. Melatonin in psychiatric disorders: a review on the melatonin involvement in psychiatry. Front Neuroendocrinol. 2001;22(1):18-32.

126. Maldonado MD, Reiter RJ, Perez-San-Gregorio MA. Melatonin as a potentia therapeutic agent in psychiatric illness. Hum Psychopharmacol. 2009;24(5): 391-400.

127. Agorastos A, Linthorst ACE. Potential pleiotropic beneficial effects of adjuvant melatonergic treatment in posttraumatic stress disorder. J Pineal Res. 2016;61(1):3-26.

128. De Crescenzo F, Lennox A, Gibson JC, Cordey JH, Stockton S, Cowen PJ, et al. Melatonin as a treatment for mood disorders: a systematic review. Acta Psychiatrica Scandinavica. 2017;136(6):549-58.

129. Pytka K, Mlyniec K, Podkowa K, Podkowa A, Jakubczyk M, Zmudzka E, et al. The role of melatonin, neurokinin, neurotrophic tyrosine kinase and glucocorticoid receptors in antidepressant-like effect. Pharmacol Rep. 2017;69(3):546-54.

130. Wang HR, Woo YS, Bahk WM. The role of melatonin and melatonin agonists in counteracting antipsychotic-induced metabolic side effects: a systematic review. Int Clin Psychopharmacol. 2016;31(6):301-6.

131. Wilhelmsen M, Amirian I, Reiter RJ, Rosenberg J, Gogenur I. Analgesic effects of melatonin: a review of current evidence from experimental and clinical studies. J Pineal Res. 2011;51(3):270-7.

132. Leone $\mathrm{M}$, Bussone $\mathrm{G}$. Melatonin in cluster headache: rationale for use and possible therapeutic potential. CNS Drugs. 1998;9(1):7-16.

133. Srinivasan V, Spence WD, Pandi-Perumal SR, Zakharia R, Bhatnagar KP, Brzezinski A. Melatonin and human reproduction: shedding light on the darkness hormone. Gynecol Endocrinol. 2009;25(12):779-85.

134. Tamura H, Nakamura Y, Korkmaz A, Manchester LC, Tan DX, Sugino N, et al. Melatonin and the ovary: physiological and pathophysiological implications. Fertil Steril. 2009;92(1):328-43.

135. Tamura H, Nakamura Y, Terron MP, Flores LJ, Manchester LC, Tan DX, et al. Melatonin and pregnancy in the human. Reprod Toxicol. 2008; 25(3):291-303

136. Tamura H, Takasaki A, Taketani T, Tanabe M, Lee L, Tamura I, et al. Melatonin and female reproduction. J Obstet Gynaecol Res. 2014;40(1):1-11.

137. Valenzuela FJ, Vera J, Venegas C, Pino F, Lagunas C. Circadian system and melatonin hormone: risk factors for complications during pregnancy. Obstet Gynecol Int. 2015;2015:825802.

138. Dragojevic Dikic S, Jovanovic AM, Dikic S, Jovanovic T, Jurisic A, Dobrosavljevic A. Melatonin: a 'Higgs boson' in human reproduction. Gynecol Endocrinol. 2015;31(2):92-101.
139. Fernando S, Rombauts L. Melatonin: shedding light on infertility? - A review of the recent literature. J Ovarian Res. 2014;7:98.

140. Turk J. Melatonin supplementation for severe and intractable sleep disturbance in young people with genetically determined developmental disabilities: short review and commentary. J Med Genet. 2003;40(11):793-6.

141. Vural EMS, Van Munster BC, De Rooij SE. Optimal dosages for melatonin supplementation therapy in older adults: a systematic review of current literature. Drugs Aging. 2014;31(6):441-51.

142. Wade A, Downie S. Prolonged-release melatonin for the treatment of insomnia in patients over 55 years. Expert Opin Investigat Drugs. 2008;17(10):1567-72.

143. Rossignol DA, Frye RE. Melatonin in autism spectrum disorders: a systematic review and meta-analysis. Dev Med Child Neurol. 2011;53(9):783-92.

144. Guenole F, Godbout R, Nicolas A, Franco P, Claustrat B, Baleyte JM. Melatonin for disordered sleep in individuals with autism spectrum disorders: systematic review and discussion. Sleep Med Rev. 2011;15(6):379-87.

145. McGrane IR, Leung JG, St Louis EK, Boeve BF. Melatonin therapy for REM sleep behavior disorder: a critical review of evidence. Sleep Med. 2015;16(1):19-26.

146. Olde Rikkert MG, Rigaud AS. Melatonin in elderly patients with insomnia. A systematic review. Z Gerontol Geriatr. 2001;34(6):491-7.

147. Sajith SG, Clarke D. Melatonin and sleep disorders associated with intellectual disability: a clinical review. J Intellect Disabil Res. 2007:51(Pt 1):2-13.

148. Heiligenstein E, Guenther G. Over-the-counter psychotropics: a review of melatonin, St John's wort, valerian, and kava-kava. J Am Coll Health. 1998;46(6):271-6.

149. Lanfumey L, Mongeau R, Hamon M. Biological rhythms and melatonin in mood disorders and their treatments. Pharmacol Ther. 2013;138(2):176-84

150. Lemoine $P$, Zisapel N. Prolonged-release formulation of melatonin (Circadin) for the treatment of insomnia. Expert Opin Pharmacother. 2012;13(6):895-905.

151. Jan JE, Wasdell MB, Reiter RJ, Weiss MD, Johnson KP, Ivanenko A, et al. Melatonin therapy of pediatric sleep disorders: recent advances, why it works, who are the candidates and how to treat. Curr Pediatric Rev. 2007;3(3):214-24.

152. Armour D, Paton C. Melatonin in the treatment of insomnia in children and adolescents. Psychiatr Bull. 2004;28(6):222-4.

153. Bellon AM. Searching for new options for treating insomnia: are melatonin and ramelteon beneficial? J Psychiatr Pract. 2006;12(4):229-43.

154. Buscemi N, Vandermeer B, Hooton N, Pandya R, Tjosvold L, Hartling L, et al. The efficacy and safety of exogenous melatonin for primary sleep disorders: a meta-analysis. J Gen Intern Med. 2005;20(12):1151-8.

155. Buscemi N, Vandermeer B, Hooton N, Pandya R, Tjosvold L, Hartling L, et al. Efficacy and safety of exogenous melatonin for secondary sleep disorders and sleep disorders accompanying sleep restriction: meta-analysis. BMJ. 2006;332(7538):385-93.

156. Cardinali DP, Golombek DA, Rosenstein RE, Brusco LI, Vigo DE. Assessing the efficacy of melatonin to curtail benzodiazepine/Z drug abuse. Pharmacol Res. 2016;109(Suppl C):12-23.

157. Herxheimer A, Petrie KJ. Melatonin for the prevention and treatment of jet lag. Cochrane Database Syst Rev. 2002;2:CD001520.

158. Zhang W, Chen XY, Su SW, Jia QZ, Ding T, Zhu ZN, et al. Exogenous melatonin for sleep disorders in neurodegenerative diseases: a meta-analysis of randomized clinical trials. Neurol Sci. 2016;37(1):57-65.

159. Wang-Weigand S, McCue M, Ogrinc F, Mini L. Effects of ramelteon $8 \mathrm{mg}$ on objective sleep latency in adults with chronic insomnia on nights 1 and 2 : pooled analysis. Curr Med Res Opin. 2009;25(5):1209-13.

160. Phillips L, Appleton RE. Systematic review of melatonin treatment in children with neurodevelopmental disabilities and sleep impairment. Dev Med Child Neurol. 2004;46(11):771-5.

161. van Geijlswijk IM, Korzilius HP, Smits MG. The use of exogenous melatonin in delayed sleep phase disorder: a meta-analysis. Sleep. 2010;33(12):1605-14.

162. Reiter RJ, Tan DX, Leon J, Kilic U, Kilic E. When melatonin gets on your nerves: its beneficial actions in experimental models of stroke. Exp Biol Med. 2005;230(2):104-17.

163. Samantaray S, Das A, Thakore NP, Matzelle DD, Reiter RJ, Ray SK, et al. Therapeutic potential of melatonin in traumatic central nervous system injury. J Pineal Res. 2009;47(2):134-42.

164. Reiter RJ, Acuna-Castroviejo D, Tan DX, Burkhardt S. Free radical-mediated molecular damage. Mechanisms for the protective actions of melatonin in the central nervous system. Ann NY Acad Sci. 2001;939:200-15. 
165. Keegan LJ, Reed-Berendt R, Neilly E, Morrall MC, Murdoch-Eaton D. Effectiveness of melatonin for sleep impairment post paediatric acquired brain injury: evidence from a systematic review. Dev Neurorehabil. 2014;17(5):355-62.

166. Hong Y, Palaksha KJ, Park K, Park S, Kim H-D, Reiter RJ, et al. Melatonin plus exercise-based neurorehabilitative therapy for spinal cord injury. J Pineal Res. 2010;49(3):201-9.

167. Reiter RJ, Sainz RM, Lopez-Burillo S, Mayo JC, Manchester LC, Tan DX. Melatonin ameliorates neurologic damage and neurophysiologic deficits in experimental models of stroke. Ann NY Acad Sci. 2003;993:35-47.

168. Cervantes M, Morali G, Letechipia-Vallejo G. Melatonin and ischemia-reperfusion injury of the brain. J Pineal Res. 2008;45(1):1-7.

169. Braam W, Smits MG, Didden R, Korzilius H, Van Geijlswijk IM, Curfs LM. Exogenous melatonin for sleep problems in individuals with intellectual disability: a meta-analysis. Dev Med Child Neurol. 2009:51(5):340-9.

170. Marrin K, Drust B, Gregson W, Atkinson G. A meta-analytic approach to quantify the dose-response relationship between melatonin and core temperature. Eur J Appl Physiol. 2013;113(9):2323-9.

\section{Submit your next manuscript to BioMed Central} and we will help you at every step:

- We accept pre-submission inquiries

- Our selector tool helps you to find the most relevant journal

- We provide round the clock customer support

- Convenient online submission

- Thorough peer review

- Inclusion in PubMed and all major indexing services

- Maximum visibility for your research

Submit your manuscript at www.biomedcentral.com/submit 